\title{
BEHIND THE CYTOKINES STORM OF SEVERE COVID-19, COULD BE HIDDEN MACROPHAGE ACTIVATION SYNDROME - A CASE REPORT
}

Rafaela Silva Guimarães Gonçalves ${ }^{1, \star}$, André da Costa Victor², Clarice Alves Esmeraldo ${ }^{1}$, Glauber Ruan Nelson Bem¹, Amalia Maria Fernandes de Sá Duarte Filha ${ }^{1}$, Ana Carolina Oliveira Cavalcanti Tavares ${ }^{3}$, Angela Luzia Branco Pinto Duarte ${ }^{1}$

1.Universidade Federal de Pernambuco, Recife (PE), Brazil; 2.Laboratório Edmar Victor, Recife (PE), Brazil; 3.Hospital Maria Lucinda, Recife (PE), Brazil.

*Corresponding author: rafa_sgg@hotmail.com

\section{BACKGROUND}

Our objective was to point out that macrophage activation syndrome (MAS) is a serious complication in COVID-19, which must be early diagnosed once immediate treatment can contribute to patient's survival.

\section{CASE REPORT}

On May 4, 2020, a 73-year-old man was admitted to the hospital with COVID-19 (on the 10th day of disease evolution). He was given oseltamivir, ivermectin, azithromycin and hydroxychloroquine by a local clinic empirically at the first day. He had history of hypertension, diabetes, chronic kidney disease and gout. On admission he was febrile $37.8^{\circ} \mathrm{C}$ and oxygen saturation(Sats) oscillating between 88 to $94 \%$ (breathing ambient air/prone position). Computed tomography (CT) showed multiple ground-glass opacities dispersed predominantly peripheral pulmonary lobes affecting about $50 \%$ (Figure1A). Laboratory results (Table1) reflected a significant lymphocytopenia, anemia and mild thrombocytopenia. His inflammatory markers were elevated: high-sensitive C-reactive protein (hsCRP) $159 \mathrm{mg} / \mathrm{L}$ (0-3), a mild high erythrocyte sedimentation rate (ESR) $48(4.5-11) \mathrm{mm} / \mathrm{h}$, and D-dimer $2.88 \mu / \mathrm{mL}(<0-0.5)$. On the same day of admission heparin in full dose, methylprednisolone $80 \mathrm{mg}$ and ceftriaxone were given. On May 6, drop in hemoglobin was noted and erythrocyte sedimentation rate did not increase proportionally, ferritin $1136(22-320) \mathrm{ng} / \mathrm{mL}$ and a myelogram had done. The myelogram had shown hemophagocytic activity (Figure 2). On May 7, the patient developed shortness of breath and his Sats decreased to $88 \%$ when breathing ambient air, and 92-94\% on 10 L of oxygen by nasal catheter. ACT was repeated and showed progressing infiltrations bilaterally reaching about $80 \%$ (Figure 1A). The patient was admitted to the ICU, ceftriaxone was changing by Piperacilina-tazobactam and teicoplanin, $2 \mathrm{~g} / \mathrm{kg}$ IVlg was started, and methylprednisolone was increased for $1000 \mathrm{mg}$ on the first day, $250 \mathrm{mg}$ on the second and third day, and then maintained with 80 $\mathrm{mg} /$ day completing ten days. After the last IVlg infusion, CT has repeated and already showing improvement (Figure 1B). Supplemental oxygen was discontinued on May 14, and his Sats level returned to 97-98\% on ambient air. The result of laboratory tests on May 14 showed recovered lymphocyte count and reduced hsCRP $2.39 \mathrm{mg} / \mathrm{L}$.

A

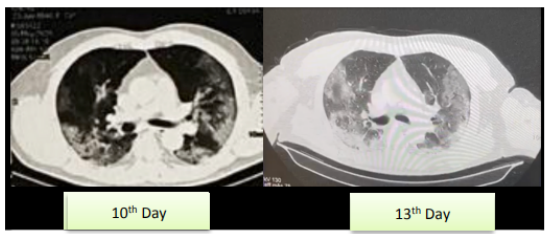

B

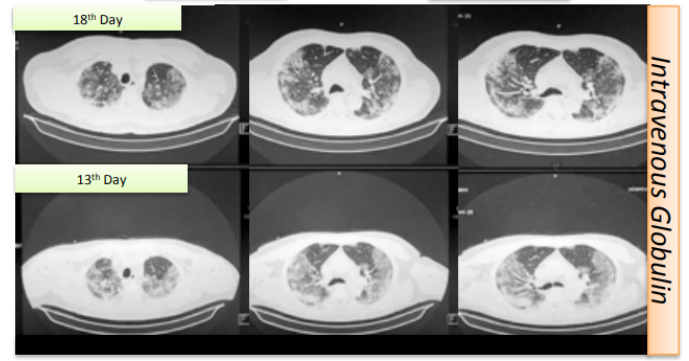

c

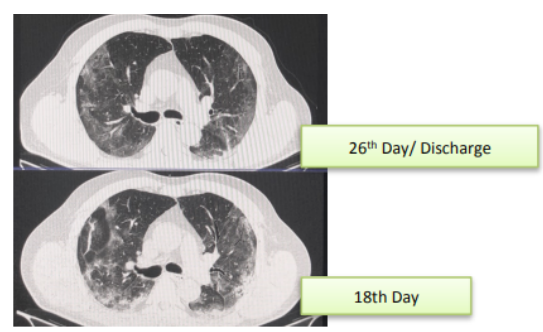

Figure 1. Chest computed tomography scan of patient: (A) 1st day of admission in the hospital and three days after, (B) before and after infusion intravenous immunoglobulin with days of illness, (C) day after the last day of infusion intravenous immunoglobulin and eight days after. 

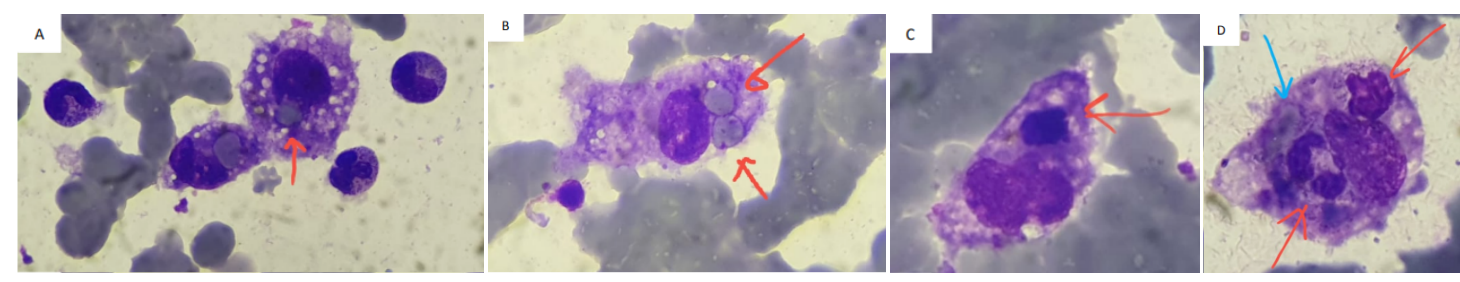

Figure 2. Myelogram. (A) and (B) both images show histiocytes phagocyting red blood cells; (C) image shows a histiocyte phagocyting a leukocyte; however, the leukocyte degeneration does not allow what kind of leukocyte is it; and (D) shows histiocyte in phagocytic activity with the presence of two polymorphonuclear cells (red arrows) and one red cell (blue arrow).

Table 1. Laboratory tests.

\begin{tabular}{|c|c|c|c|c|c|c|c|c|c|}
\hline \multirow{3}{*}{$\begin{array}{c}\text { Measures } \\
\text { (Normal ranges) }\end{array}$} & \multicolumn{8}{|c|}{ Illness days } & \multirow[b]{3}{*}{ 26th } \\
\hline & \multirow[b]{2}{*}{ 5th } & \multicolumn{2}{|l|}{ 1st Hosp } & \multicolumn{3}{|c|}{$1 \mathrm{st}$ ICU } & \multirow[b]{2}{*}{ 18th } & \multirow[b]{2}{*}{ 20th } & \\
\hline & & & 11th & 12th & & 14th & & & \\
\hline WBC $\left(10^{9} /\right.$ L $) 4.5-11$ & 4.8 & 7.5 & 11.5 & 9.9 & 8.7 & 9.8 & 7.8 & 8.2 & 10.4 \\
\hline RBC $\left(10^{12} / L\right) 4.5-5.9$ & 4.53 & 3.48 & 3.63 & 3.47 & 3.44 & 3.8 & 3.34 & 3.6 & 3.31 \\
\hline $\mathrm{Hb}(\mathrm{g} / \mathrm{dL}) 13.5-17.5$ & 13.5 & 10.8 & 11.2 & 10.8 & 10.5 & 11.5 & 10.4 & 11 & 10.4 \\
\hline PLT (10/L) 150-450 & 163 & 109 & 131 & 160 & 172 & 205 & 224 & 252 & 292 \\
\hline NEUT $\left(10^{9} /\right.$ L) 1.6-7.7 & 2.6 & 6.3 & 9.6 & 8.81 & 7.48 & 8.42 & 6.2 & 6.3 & 9.15 \\
\hline LYM $\left(10^{9} / L\right) 1.1-3.9$ & 1.6 & 0.6 & 1.38 & 0.59 & 0.78 & 0.68 & 0.99 & 1.19 & 1.0 \\
\hline $\operatorname{ESR}(\mathrm{mm} / \mathrm{h})<20$ & NR & 48 & 69 & 36 & NR & NR & NR & 35 & $N R$ \\
\hline hsCRP (mg/L) 0-3 & 11.94 & 159.1 & 187.8 & 124.7 & 92.7 & 80.4 & 14.3 & 2.39 & 3.5 \\
\hline $\mathrm{SF}(\mathrm{ng} / \mathrm{mL}) 22-320$ & 426 & NR & 1136 & 1300 & 876 & 869 & 585 & NR & NR \\
\hline Tn (ng/L) 0-14 & NR & NR & 14 & 10 & NR & NR & NR & NR & NR \\
\hline LDH (U/L) 120-246 & 180 & 386 & NR & NR & 360 & 375 & NR & 256 & 190 \\
\hline ALB (g/dL) 3.4-4.8 & 4.1 & 2.8 & NR & NR & 2.4 & NR & NR & NR & NR \\
\hline TBIL (mg/dL) 0.3-1.2 & NR & NR & 0.23 & NR & 0.3 & 0.4 & NR & NR & NR \\
\hline $\operatorname{ALT}(U / L)$ 6-41 & 24 & 17 & 16 & NR & 19 & 29 & NR & 25 & NR \\
\hline AST (U/L) 15-37 & 34 & 35 & 38 & NR & 42 & 52 & NR & 24 & NR \\
\hline$\gamma-\mathrm{GT}(\mathrm{U} / \mathrm{L})$ 15-85 & NR & NR & 141 & NR & 179 & NR & NR & NR & NR \\
\hline CRE (mg/dL) 0.5-1.3 & 0.9 & 2.23 & 1.99 & 1.64 & 1.8 & 1.69 & 1.66 & 1.63 & 1.44 \\
\hline $\operatorname{Ur}(\mathrm{mg} / \mathrm{dL}) 15-50$ & 40 & 60 & 61 & 62 & 58 & 49 & 80 & 80 & 82 \\
\hline CK (U/L) 39-308 & 55 & NR & 115 & NR & NR & NR & NR & NR & 43 \\
\hline D-dimer ( $\mu \mathrm{g} / \mathrm{mL})$ 0-0.5 & 2 & 2.88 & $>20$ & 2.61 & NR & 1.59 & 1.81 & 1.35 & 0.97 \\
\hline $\mathrm{FIB}(\mathrm{mg} / \mathrm{dL})$ 200-400 & 347 & NR & 616 & 647 & NR & NR & NR & NR & NR \\
\hline
\end{tabular}

WBC: white blood cell count; RBC: red blood cell count; Hb: hemoglobin; PLT: platelet count; NEUT: absolute neutrophil count; LYM: absolute lymphocyte count; ESR: erythrocyte sedimentation rate; NR: not realized; hSCRP: hypersensitive C-reactive protein; SF: serum ferritin; Tn: troponin; LDH: lactate dehydrogenase; ALB: albumin; TBIL: total bilirubin; ALT: alanine aminotransferase; AST: aspartate aminotransferase; -GT: -glutamyltransferase; CRE: creatinine; Ur: urea; CK: creatine kinase; FIB: fibrinogen.

\section{CONCLUSION}

It is necessary to keep in mind that severe COVID-19 is a hyperferritinemic syndrome and can degenerate into MAS without the classic signs of primary MAS, such as organomegalies. The assessment of each patient individually and the interpretation of clinical and laboratory signs are the key to for early and correct diagnosis, which implies an effective therapy.

\section{KEYWORDS}

COVID-19, MAS, IVIG, Methylprednisolone. 